\title{
Potential MRI Contrast Agents Based on Micellar Incorporation of Amphiphilic Bis(alkylamide) Derivatives of $\left[(\text { Gd-DTPA })\left(\mathrm{H}_{2} \mathrm{O}\right)\right]^{2-}$
}

Kristof Kimpe,${ }^{[\mathrm{a}]}$ Tatjana N. Parac-Vogt, ${ }^{[\mathrm{a}]}$ Sophie Laurent, ${ }^{[\mathrm{b}]}$ Corinne Piérart ${ }^{[\mathrm{b}]}$, Luce Vander Elst, ${ }^{[\mathrm{b}]}$ Robert N. Muller ${ }^{[\mathrm{b}]}$ and Koen Binnemans ${ }^{[\mathrm{a}]}$

${ }^{[a]}$ Katholieke Universiteit Leuven, Department of Chemistry, Celestijnenlaan 200F, B-3001 Leuven, Belgium.

[b] NMR laboratory, Department of Organic Chemistry, University of Mons-Hainaut, B-7000 Mons, Belgium.

MRI (magnetic resonance imaging) contrast agents are routinely used in medicine because they are able to produce reliable results that help in rapid clinical interpretation of images and simultaneously improve the patient turnover. Most of the commonly used contrast agents achieve their effect by enhancing the relaxation rate of water protons in tissues. In general contrast agents consist of a paramagnetic metal centre, typically $\mathrm{Gd}^{3+}$, which is complexed with a strong chelating ligand, since the free metal ions are toxic at the concentrations needed for diagnosis ${ }^{[1-2]}$.

In recent years complexes of lanthanides with diethylenetriamine$N, N, N,{ }^{\prime} N$, ' $N$ "'-pentaacetate $\left(\mathrm{DTPA}^{5-}\right)$ and with its amide derivatives have attracted considerable attention. The anionic $\left[\operatorname{Gd}(\mathrm{DTPA})\left(\mathrm{H}_{2} \mathrm{O}\right)\right]^{2-}$, the first contrast agent approved for use in humans, is nowadays routinely used in clinical magnetic resonance imaging for contrast enhancement under the name Magnevist ${ }^{\circledR}$ (Schering, Berlin, Germany). This paramagnetic complex contains one inner-sphere water molecule ${ }^{[3-6]}$ that exchanges rapidly ${ }^{[7]}$ with the bulk water in the human body, therefore providing an efficient mechanism for the enhancement of the relaxation rates of the water protons.

In attempt to achieve higher proton relaxivity, DTPA-bisamide derivatives with alkyl chains consisting of 14, 16, and 18 carbon atoms were synthesized and complexes of various trivalent lanthanide ions $(\mathrm{Ln}=\mathrm{Gd}, \mathrm{La}, \mathrm{Pr}, \mathrm{Eu})$ were formed. Variable temperature proton NMR spectroscopy of paramagnetic praseodynium(III) and europium(III) complexes revealed that long aliphatic substituents considerably increase the energy barrier for the intramolecular rearrangement around the lanthanide ion. The gadolinium(III) complexes were incorporated into mixed micelles (DPPC and Tween $80^{\circledR}$ ) and photon correlation spectroscopy showed that the mean sizes of all the micelles were within the same range. The NMRD-curves of all three DTPAbisamide-gadolinium complexes incorporated in mixed micelles display higher relaxivity values than the commercially available Gd-DTPA contrast agent. The higher relaxivity obtained for the micellar DTPA-bisamide-gadolinium complexes with $\mathrm{C}_{14}$ and $\mathrm{C}_{16}$ chains as compared to the micellar DTPA-bisamide-Gd(III) complex with $\mathrm{C}_{18}$ chain could be attributed to the fact that the alkyl chain consisting of 18 carbon atoms is longer than the alkyl chain of the major component of the micelles, DPPC, in which it is inserted. This allows an increased mobility of the polar head and hence a lower relaxivity. 
<smiles>O=C([O-])CN(CCN(CC(=O)[O-])CC(=O)[O-])CCN(CC(=O)NC(=O)[O-])CC(=O)Nc1ccccc1</smiles>

Schematic representation of a lanthanide DTPA-bisamide derivative with an alkyl chain of consisting of 18 carbon atoms.

\section{$\underline{\text { References: }}$}

1. Rinck, PA. Magnetic Resonance in Medicine; Blackwell Scietific Publications; Oxford, UK, 1993.

2. S. Aime, M. Botta, M. Fasano, E. Terreno "Lanthanide(III) chelates fot NMR biomedical applications" Chemical Society Reviews 27 (1998) 19-29.

3. C. C. Bryden, C. N. Reilley, Anal.Chem. 1982, 54, 610-615.

4. J. A. Peters, Inorg. Chem. 1988, 27, 4686-4691.

5. C. F. G. C. Geraldes, A. D. Sherry, W. P. Cacheris, K. T. Kuan, R.D. Brown III, S. H. Koenig, M. Spiller, Magn. Reson. Med. 1988, 8, 191-199.

6. C. A. Chang, H. G. Brittain, J. Telser, M. F. Tweedle, Inorg. Chem. 1990, 29, 4468-4473.

7. K. Micskei, L. Helm, E. Brucher, A. E. Merbach, Inorg. Chem. 1993, 32, 3844-3850. 